\title{
Presentación
}

\section{Contribución al proceso de unificación del Derecho privado}

\author{
Inmaculada Herbosa Martínez \\ Profesora Titular Derecho civil. Universidad de Deusto \\ inmaculada.herbosa@deusto.es
}

doi: http://dx.doi.org/10.18543/ced-61-2019pp19-22

Resumen: Este monográfico incluye varios trabajos relacionados con cuestiones de Derecho privado y que se abordan, fundamentalmente, desde la perspectiva del Derecho europeo aunque también del Derecho comparado. Las materias tratadas son diversas y, aparentemente, sin conexión entre sí, pues algunas abordan cuestiones surgidas de la nueva realidad social en la que vivimos, relacionadas con la sociedad de la información y las prácticas comerciales abusivas; y otras versan sobre institutos tradicionales del Derecho civil, como la prescripción, que es sometida a revisión. Todas ellas, sin embargo, tienen un rasgo común, que es el interés dogmático y práctico de las materias tratadas, y su contribución a la unificación, entendida en sentido amplio, del Derecho privado europeo.

Palabras clave: Europeización del Derecho privado, unificación del Derecho privado, contratación electrónica, protección de datos, documento digital, prácticas comerciales abusivas, prescripción extintiva.

En el momento presente es incuestionable la penetración del llamado Derecho europeo - e internacional - en los ordenamientos internos de los países que integran la Unión Europea. La labor del jurista no es ya advertir de su influencia en dichos ordenamientos, que es obvia, sino estudiar los nuevos retos que plantea esta disciplina. Cuando se habla de Derecho privado europeo nos referimos, lógicamente, a los instrumentos vinculantes y textos académicos a través de los que se pretende la deseable armonización en el ámbito de la Unión Europa, entre los que se encuentran iniciativas tan meritorias como los Principios de Derecho europeo o el Borrador del Marco Común de Referencia, calificada por algunos autores, sin incurrir en exageración, como la obra más colosal llevada a cabo después del Digesto.

Además, a esta europeización e internacionalización contribuye la labor desarrollada por los académicos para abordar y resolver problemas, por así decir, universales, utilizando la ciencia del Derecho comparado según fue entendida por SALEILLES, distinta de la mera comparación de diferentes 
regulaciones. Este enfoque supone remontarse al fundamento de cada institución, comprender los rasgos propios de los distintos ordenamientos privados nacionales y abstraer las notas comunes que conforman el sustrato común que subyace a los ordenamientos europeos (al menos el de aquellos tenidos en cuenta en el proceso de abstracción anteriormente mencionado). Ciertamente, este «Derecho» no constituye propiamente un Derecho privado común, ya que no dimana de una institución europea ni ha sido compilado ni sistematizado por académicos, pero permite dar soluciones nuevas a viejos problemas sobre la base de principios generales comunes que subyacen a una concreta regulación, que contribuyen de otra forma a la unificación del Derecho privado.

Este monográfico incluye trabajos sobre diferentes materias de Derecho privado, que responden en su mayor parte al primero de estos enfoques. Pero todos ellos prestan atención al proceso de unificación de esta disciplina a nivel europeo en el sentido amplio arriba explicado.

Dentro de un primer bloque se aborda un tema fundamental en la sociedad actual (la llamada sociedad de la información), que es el relativo a «La pérdida de privacidad en la contratación electrónica». Como es sabido, en el ámbito de la Unión Europea se han adoptado varios instrumentos que se ocupan, por separado, de la protección de datos, la contratación electrónica y del suministro de contenidos o servicios digitales (entre ellas, la Directiva 2019/770/UE relativa a determinados aspectos de los contratos de suministro de contenidos y servicios digitales). Sin embargo, ninguno de estos instrumentos trata del problema concreto que se aborda en el mencionado trabajo, que es analizar la interacción mutua de estas normas, y sus posibles carencias, cuando los datos personales se ponen en circulación con ocasión de la contratación de un bien o un servicio en el mercado digital. Datos, sobre los que el consumidor tiene escaso control una vez que los ha suministrado, y que, a su vez, son de gran interés para el empresario en cuanto son susceptibles de diversas formas de tratamiento (elaboración de perfiles, estudios de comportamiento o reventa de datos a terceros). En este contexto se analizan las medidas de control que tiene el usuario sobre los permisos concedidos para el tratamiento de sus datos al proveedor de bienes y servicios; en particular, en el contrato de suministro de contenidos digitales a cambio de información personal, comprendido en el ámbito de aplicación de la Directiva 2019/770/UE anteriormente citada.

También en el ámbito del entorno digital, un segundo trabajo trata del concepto de «documento escrito» en el Derecho privado europeo actual, y con ocasión de ello, el concepto de documento electrónico en relación con el concepto más amplio de documento informático sobre la base de lo establecido en el Reglamento 910/2014, de 23 de julio. Tomando como base una distinción típica de la legislación italiana entre escritos y reproduc- 
ciones mecánicas, se concluye que en el Derecho privado europeo debe entenderse superada cualquier definición de «escrito» como mera representación o reproducción de palabras en forma visible, por cuanto dicha expresión comprende cualquier comunicación que implique la memorización de su propio contenido. A favor de esta argumentación se utiliza la definición amplia establecida por los Principios Unidroit, comprensiva de cualquier representación de hechos almacenados en medios duraderos a través de grabaciones reproducibles por medios mecánicos, siempre que se utilicen como un medio declarativo de voluntad.

Un tercer trabajo, que versa sobre la Directiva 2005/29/CE sobre prácticas comerciales desleales o abusivas, se ocupa de los remedios o acciones individuales de las que disponen los consumidores que, como consecuencia de una práctica abusiva, han suscrito contratos no queridos o queridos sólo en parte. Teniendo en cuenta que la regulación de estas medidas se ha dejado enteramente a los Estados miembros, se producen grandes divergencias entre los mismos: mientras algunos han previsto soluciones ad hoc, muy diferentes entre sí, en otros se aplican, con algunos matices, los remedios generales del Derecho de contratos. En el trabajo se cuestiona si, pese a ello, la aplicación de otras Directivas europeas (Directivas 93/13/CE; 1999/44/CE y 2011/83/UE) dictadas en el ámbito del Derecho de consumo, que interfieren con la disciplina de prácticas abusivas, permiten alcanzar, para los supuestos comprendidos en sus respectivos ámbitos de aplicación, remedios individuales y efectivos armonizados para los consumidores a nivel comunitario. Y, en su caso, si podría utilizarse el principio de buena fe para fundar en él dichos remedios.

Con el segundo enfoque al que nos referíamos más arriba, se incluye un cuarto trabajo que trata sobre la prescripción extintiva o liberatoria. Dicho trabajo constituye una profunda reflexión sobre este tradicional instituto, que no sólo goza del «embrujo» que le atribuye el autor, sino que, además, es inherente a cualquier ordenamiento jurídico. Es inimaginable que cualquier reclamación o ejercicio de acciones no esté sometido a un límite temporal, aunque no por ello sea una figura sencilla, ni en su configuración dogmática ni a la hora de establecer diferencias con la caducidad. Además de una visión general del instituto, el trabajo trata de averiguar la ratio a la que obedece la fijación de unos u otros plazos de duración y, con carácter previo, a qué responde la opción del legislador de haber optado por diferentes plazos para el ejercicio de acciones, en lugar de plazos únicos. Este análisis se realiza tomando como base textos europeos y otros de ámbito más amplio como los Principios Unidroit, así como la regulación del instituto en diferentes países de la Unión Europea, de los que se extraen principios y rasgos comunes para una reconstrucción dogmática de esta figura. 


\section{Sobre la autora}

Inmaculada Herbosa Martínez es Profesora Titular de Derecho civil en la Universidad de Deusto, entre ellas Derecho contractual europeo. Imparte docencia en diferentes asignaturas en Derecho patrimonial privado. Profesora visitante en Boston College, Georgetown, Real Colegio de la Complutense en Harvard, y London School of Economics, entre otras universidades extranjeras. Ha sido vicedecana de Ordenación Académica y de Investigación y Postgrados. Con dos sexenios reconocidos de investigación ha formado parte de diferentes equipos de la Universidad de Deusto. En el momento presente es miembro del equipo «Integración europea y Derecho patrimonial en un contexto global». Es autora única de cuatro monografías, numerosas publicaciones en obras colectivas y artículos en revistas especializadas, así como investigadora principal de varios proyectos de investigación. 


\section{Derechos de autor}

Los derechos de autor (para la distribución, comunicación pública, reproducción e inclusión en bases de datos de indexación y repositorios institucionales) de esta publicación (Cuadernos Europeos de Deusto, CED) pertenecen a la editorial Universidad de Deusto. El acceso al contenido digital de cualquier número de Cuadernos Europeos de Deusto es gratuito inmediatamente después de su publicación. Los trabajos podrán leerse, descargarse, copiar y difundir en cualquier medio sin fines comerciales y según lo previsto por la ley; sin la previa autorización de la Editorial (Universidad de Deusto) o el autor. Así mismo, los trabajos editados en CED pueden ser publicados con posterioridad en otros medios o revistas, siempre que el autor indique con claridad y en la primera nota a pie de página que el trabajo se publicó por primera vez en CED, con indicación del número, año, páginas y DOI (si procede). Cualquier otro uso de su contenido en cualquier medio o formato, ahora conocido o desarrollado en el futuro, requiere el permiso previo por escrito del titular de los derechos de autor.

\section{Copyright}

Copyright (for distribution, public communication, reproduction and inclusion in indexation databases and institutional repositories) of this publication (Cuadernos Europeos de Deusto, CED) belongs to the publisher University of Deusto. Access to the digital content of any Issue of Cuadernos Europeos de Deusto is free upon its publication. The content can be read, downloaded, copied, and distributed freely in any medium only for non-commercial purposes and in accordance with any applicable copyright legislation, without prior permission from the copyright holder (University of Deusto) or the author. Thus, the content of CED can be subsequently published in other media or journals, as long as the author clearly indicates in the first footnote that the work was published in CED for the first time, indicating the Issue number, year, pages, and DOI (if applicable). Any other use of its content in any medium or format, now known or developed in the future, requires prior written permission of the copyright holder. 